\title{
Gold recovery from waste printed circuit boards of mobile phones by using microwave pyrolysis and hydrometallurgical methods
}

\author{
Yu-Fong Huang ${ }^{1}$, Szu-Ling Chou ${ }^{1}$ and Shang-Lien Lo ${ }^{1,2^{*}}$
}

\begin{abstract}
Recycling of waste printed circuit boards (PCBs) has attracted increasing attention because of its high annually produced amount and high content of gold. In this study, gold recovery from waste PCBs was carried out by using the processes including microwave pyrolysis, acid leaching, solvent extraction and oxidative precipitation. The leaching efficiency of copper was approximately $95 \%$ when using a lixiviant composed of sulfuric acid and hydrogen peroxide, and the leaching efficiencies of gold were approximately 59, 95 and $95 \%$ by using thiourea, thiosulfate and aqua regia, respectively. The gold ions contained in the leachate previously produced by the leaching processes were not satisfactorily extracted by using organic solvents including di-(2-ethylhexyl)phosphoric acid, tributyl phosphate, dibutyl carbitol and trioctylamine, so the leachate was decided to bypass solvent extraction and directly apply to the oxidative precipitation process. By using the oxidants of hydrogen peroxide and perchloric acid, the precipitation efficiencies of gold were approximately 95 and $99 \%$, and the final recovery rates were approximately 90 and 93\%, respectively. The high recovery rates of gold can be attributable to the use of microwave pyrolysis that prevents the loss of gold caused by shredding and grinding processes. In addition, perchloric acid can provide higher selectivity for gold recovery than hydrogen peroxide. The maximum processing capacity of microwave pyrolysis of waste PCBs would be approximately $1.23 \mathrm{~kg}$. The gold recovered from $1 \mathrm{t}$ of waste PCBs can be sold for approximately USD 10,000, and thus the return on investment can be as high as approximately $1400 \%$.
\end{abstract}

Keywords: Waste printed circuit boards, Gold recovery, Microwave pyrolysis, Acid leaching, Oxidative precipitation

\section{Introduction}

Electronic waste (e-waste), which refers to electrical and electronic equipment and its assemblies that have been discarded as waste without the intent to reuse [1], is one of the most rapidly growing waste segments in the world [2]. The amount of e-waste doubled between 2009 and 2014 [2]. The world had generated $53.6 \mathrm{Mt}$ of e-waste in 2019, and the waste stream could reach 74.7 Mt by 2030

\footnotetext{
* Correspondence: sllo@ntu.edu.tw

${ }^{1}$ Graduate Institute of Environmental Engineering, National Taiwan University, Taipei 10617, Taiwan

${ }^{2}$ Water Innovation, Low Carbon and Environmental Sustainability Research Center, National Taiwan University, Taipei 10617, Taiwan
}

[3]. In general, e-waste contains valuable materials and also hazardous or toxic substances [4-6]. In most cases, recycling factories just focus on the recovery of valuable materials (in particular precious metals) while release hazardous or toxic substances into the surroundings, resulting in threats to the environment and human health [7]. The precious metals, such as gold, silver and palladium, are widely used as contact materials and plating layers due to high electric conductivity and chemical stability [8]. Compared with other kinds of e-waste, there are the highest contents of precious metals in waste printed circuit boards (PCBs) and

(c) The Author(s). 2022 Open Access This article is licensed under a Creative Commons Attribution 4.0 International License, which permits use, sharing, adaptation, distribution and reproduction in any medium or format, as long as you give

appropriate credit to the original author(s) and the source, provide a link to the Creative Commons licence, and indicate if changes were made. The images or other third party material in this article are included in the article's Creative Commons licence, unless indicated otherwise in a credit line to the material. If material is not included in the article's Creative Commons licence and your intended use is not permitted by statutory regulation or exceeds the permitted use, you will need to obtain permission directly from the copyright holder. To view a copy of this licence, visit http://creativecommons.org/licenses/by/4.0/. 
mobile phones [2]. Besides, the precious metals in waste $\mathrm{PCBs}$ are ten times more abundant than in their respective natural ores [9]. Since waste PCBs possesses such high economic value, its recycling has attracted much attention in recent years $[5,10,11]$.

The recovery of base and precious metals from waste PCBs can be carried out by using hydrometallurgical, pyrometallurgical and electrometallurgical methods. In comparison with pyrometallurgical methods, hydrometallurgical treatments possess several advantages, such as lower capital cost, lower environmental impact, higher metal recovery and easier management $[12,13]$. Hydrometallurgical processes include three major steps: leaching to dissolve metals, purification to separate metals via selective chemical reactions, and metal recovery as a solid product [14]. In conventional leaching methods, mineral acids or cyanide-based chemicals are employed as major lixiviants [5]. Some of the traditional lixiviants are quite harmful, such as cyanide and aqua regia. Thus, there has been increasing interest on metal recovery using environmentally friendly lixiviants, including thiosulfate, thiourea and halides [15]. Recovering precious metals from waste PCBs is generally the second stage after the recovery of base metals [13]. This is because that it is easier to leach out base metals than precious metals. Through leaching process, metals in waste PCBs are dissolved into solution (leachate). To obtain final metal products, the leachate needs to be further processed for the purposes of purification and recovery [5]. A number of methods have been studied, such as solvent extraction, precipitation, cementation, ion exchange, adsorption and electrowinning $[16,17]$. To select suitable purification and recovery processes, it is necessary to consider several factors such as the concentrations of target metals and impurities in the leachate, the property of lixiviant, and the reaction condition in leaching process $[5,12]$.

Owing to accumulated amounts and material contents, mobile phones have become a crucial secondary source of valuable materials including base and precious metals as well as rare earth elements (REEs) $[18,19]$. The PCBs of mobile phones contain higher amounts of valuable metals than those of other electrical and electronic devices [20], and precious metals are the most attractive resources [21]. Therefore, in addition to the contributions to environmental protection and resource conservation, metal recovery from waste PCBs of mobile phones is of high economic value. Traditionally, the pretreatment of e-waste for resource recovery is carried out by using shredding or grinding process that can lead to the loss of precious metals up to $40 \%$ [22]. A number of studies have shown that the gold recovery rate from waste PCBs can be higher than $90 \%$ by using hydrometallurgical methods [21, 23-25]. However, the gold recovery rates need to be adjusted due to the metal loss during shredding and grinding processes. When the loss of precious metals during shredding and grinding processes is considered, the actual gold recovery rates of these literature reports would be only $50-60 \%$, much lower than the result of this study that will be mentioned hereafter. Thus, in this study, the waste PCBs was pretreated by using microwave pyrolysis to replace the sizereduction process. Rapid, efficient and selective heating can be achieved by using microwave heating [26, 27]. It has been reported that microwave pyrolysis is a useful pretreatment technique for the delamination of waste PCBs [28]. Hydrometallurgical methods, including leaching, solvent extraction and precipitation, were used to recover gold from waste PCBs as much as possible. The final recovery rate of gold was determined to evaluate the performance of the experimental procedures used in this study. The novelty of this study is the high gold recovery rate from waste PCBs by using microwave pyrolysis as a pretreatment process to replace shredding and grinding methods and thus to prevent the loss of precious metals. In addition, favorable recovery rate of gold may represent that the combination of microwave pyrolysis and hydrometallurgical methods is appropriate to recover gold from waste PCBs.

\section{Materials and methods}

\subsection{Materials}

The waste PCBs of a certain mobile phone were acquired from a local resource recycling factory. The double sides of the specific waste PCB are shown in the Supplementary Materials (Fig. S1). The dimensions of the as-received waste PCBs were approximately $12 \times 6.2$ $\mathrm{cm}$, with the weight of approximately $20 \mathrm{~g}$. The waste PCBs were washed by deionized water, immersed in isopropyl alcohol with ultrasonic oscillation for $30 \mathrm{~min}$, oven-dried at $105^{\circ} \mathrm{C}$ for $24 \mathrm{~h}$, and then cut into ten smaller pieces with the dimensions of approximately $3.1 \times 2.4 \mathrm{~cm}$. The metal composition of the waste PCBs is shown in Table 1. The waste PCBs was composed of $55.9 \mathrm{wt} \%$ copper, $5.2 \mathrm{wt} \%$ tin, $2.4 \mathrm{wt} \%$ calcium, and 1.6 wt\% aluminum, whereas the contents of other metals were all less than $1 \mathrm{wt} \%$. The contents of silver, gold, palladium and platinum were 516, 180, 158 and 35 ppmw, respectively.

\subsection{Experimental methods}

After washing and cutting, the gold recovery from waste PCBs was carried out by using a sequence of methods including microwave pyrolysis, leaching, solvent extraction and oxidative precipitation, as illustrated in Fig. 1. Each experiment was repeated in triplicate to obtain mean and standard deviation values as the experimental results of this study. 
Table 1 Metal composition of waste PCBs

\begin{tabular}{llllll}
\hline Metal & Content $(\boldsymbol{w t} \%)$ & Metal & Content $(\mathbf{p p m w})$ & Metal & Content $(\mathbf{p p m w})$ \\
\hline $\mathrm{Cu}$ & 55.87 & $\mathrm{Zn}$ & 974 & $\mathrm{Pd}$ & 158 \\
$\mathrm{Sn}$ & 5.21 & $\mathrm{Mg}$ & 856 & $\mathrm{Cr}$ & 139 \\
$\mathrm{Ca}$ & 2.41 & $\mathrm{Na}$ & 569 & $\mathrm{Te}$ & 103 \\
$\mathrm{Al}$ & 1.63 & $\mathrm{Ag}$ & 516 & $\mathrm{Ru}$ & 93 \\
$\mathrm{Ni}$ & $\mathrm{Bi}$ & 509 & $\mathrm{Ga}$ & 45 \\
$\mathrm{Fe}$ & 0.32 & $\mathrm{~K}$ & 399 & $\mathrm{Pt}$ & 35 \\
\end{tabular}

\subsubsection{Microwave pyrolysis}

The microwave pyrolysis of waste PCBs was conducted by a single-mode microwave oven operating at $2.45 \mathrm{GHz}$ with a maximum microwave power level of $2000 \mathrm{~W}$. A process flow diagram illustrating the overall microwave pyrolysis system, including microwave oven components, control panel, power meter, refrigerated circulator, reaction cavity, thermocouple, gas cylinder, vacuum pump, condenser, collector and flow meters, can be found elsewhere [29]. Approximately $20 \mathrm{~g}$ of waste PCBs was used for each microwave pyrolysis experiment. To maintain the inert atmosphere of reaction cavity, it was purged by pure nitrogen gas at a flow rate of $100 \mathrm{~mL} \mathrm{~min}^{-1}$. After sufficient purging, the microwave oven was turned on and switched to the microwave power levels of 150, 200, 250, 300, 350 and $400 \mathrm{~W}$ for $60 \mathrm{~min}$. After microwave pyrolysis, the pyrolyzed PCBs were stored in a desiccator prior to the following leaching process.

\subsubsection{Leaching}

The leaching process included two stages. Firstly, the pyrolyzed PCBs were immersed in a solution containing $120 \mathrm{~mL}$ of sulfuric acid with the concentration of 1 , 2, or 4.5 M. Another test was carried out by using the lixiviant containing $120 \mathrm{~mL}$ of $2 \mathrm{M}$ sulfuric acid and $20 \mathrm{~mL}$ of hydrogen peroxide (35\%). The solution was stirred at $400 \mathrm{rpm}$ for $3 \mathrm{~h}$ at $30^{\circ} \mathrm{C}$, and then it rested for $24 \mathrm{~h}$. The second stage leaching was carried out by using three different lixiviants: thiourea, thiosulfate and aqua regia, at the solid to liquid ratio of 1:50. The thiourea lixiviant solution contained $20 \mathrm{~g} \mathrm{~L}^{-1}$ of thiosulfate, $28.25 \mathrm{~g} \mathrm{~L}^{-1}$ of ferric sulfate heptahydrate and $10 \mathrm{~g} \mathrm{~L}^{-1}$ of sulfuric acid. The thiosulfate lixiviant solution contained $0.1 \mathrm{M}$ of ammonium thiosulfate, $0.015 \mathrm{M}$ of copper sulfate and $0.2 \mathrm{M}$ of ammonia. The aqua regia lixiviant solution was a mixture of nitric acid and hydrochloric acid in a molar ratio of 3:1. During the second stage leaching experiment, the solution was stirred at $400 \mathrm{rpm}$ for 2 $\mathrm{h}$, and the temperature was kept constant at $60^{\circ} \mathrm{C}$. After the process, the solution rested for $24 \mathrm{~h}$ prior to characterization of metal ions.

\subsubsection{Solvent extraction}

The solvent extraction of the leachate produced by twostage leaching of pyrolyzed PCBs was carried out by using four different organic solvents: di-(2-ethylhexyl) phosphoric acid (D2EHPA), tributyl phosphate (TBP), dibutyl carbitol (DBC) and trioctylamine (TOA). The solvent extraction experiments were conducted using $0.25,0.5$ and $1 \mathrm{M}$ organic solvent at the oil to aqueous $(\mathrm{O} / \mathrm{A})$ ratios of $1 / 1,1 / 2$ and $1 / 5$. The organic phase was balanced by kerosene. The organic and aqueous phases were mixed by a mechanical agitator at a speed of 400 rpm for $30 \mathrm{~min}$ at room temperature, and then the

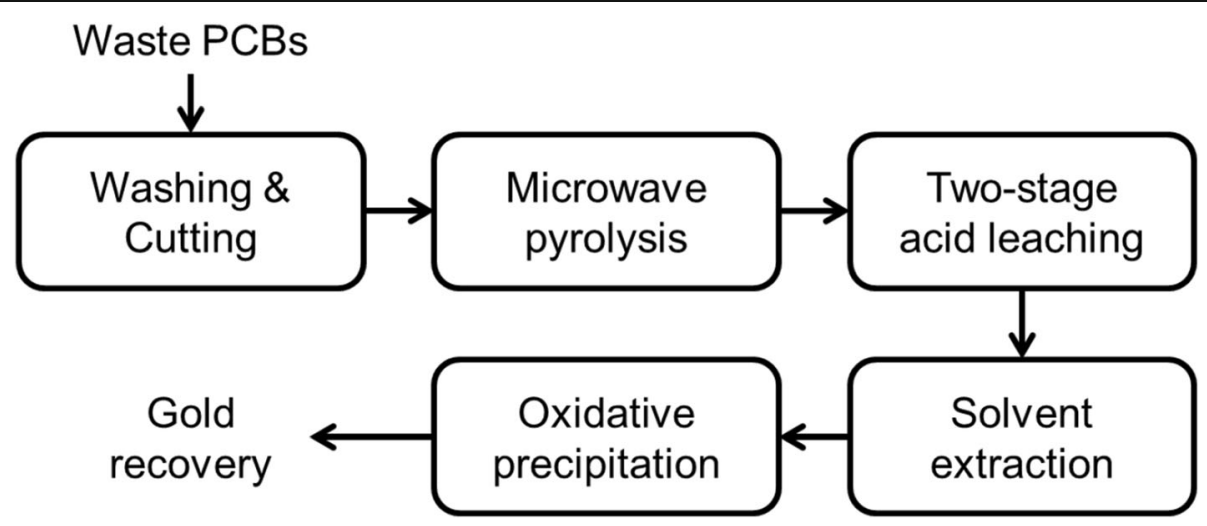

Fig. 1 Experimental procedures of gold recovery from waste PCBs 
mixed solution rested for $10 \mathrm{~min}$ to stratify the two phases.

\subsubsection{Oxidative precipitation}

The oxidative precipitation process was carried out by adding $1 \mathrm{~mL}$ of hydrogen peroxide, hypochlorous acid or perchloric acid to $50 \mathrm{~mL}$ of the solution produced by two-stage leaching of pyrolyzed PCBs. The solution was stirred at a speed of $400 \mathrm{rpm}$ for $30 \mathrm{~min}$ at room temperature, and then it rested for $24 \mathrm{~h}$. The precipitate was separated from the solution by membrane filtration, and the concentration of gold in the filtrate was analyzed.

\subsection{Analytical methods}

The microwave-assisted acid digestion of waste PCBs was carried out according to U.S. EPA Method 3052. In each digestion tube, there were approximately $0.25 \mathrm{~g}$ of finely ground waste PCBs and a digestion solution. For comparison, the digestion solution was either aqua regia or reverse aqua regia. The aqua regia solution contained $3 \mathrm{~mL}$ of nitric acid, $9 \mathrm{~mL}$ of hydrochloric acid, $1 \mathrm{~mL}$ of hydrofluoric acid, and $3 \mathrm{~mL}$ of deionized water. The reverse aqua regia solution contained $9 \mathrm{~mL}$ of nitric acid, $3 \mathrm{~mL}$ of hydrochloric acid, $1 \mathrm{~mL}$ of hydrofluoric acid, and $3 \mathrm{~mL}$ of deionized water. During the acid digestion process, the temperature was increased to $190^{\circ} \mathrm{C}$ in 30 min and then kept constant for $20 \mathrm{~min}$. After filtration by using a membrane filter $(0.45 \mu \mathrm{m}$ of pore size), the concentrations of metal ions in the digested solution were determined by using an Agilent 720-ES Inductively Coupled Plasma-Optical Emission Spectrometer (ICPOES). The calibration curves for copper and gold concentrations versus ICP-OES intensity are illustrated in Fig. S2. Because the relative standard deviation of ICPOES analysis results was less than $5 \%$, the reproducibility of the analysis should be satisfactory. The thermogravimetric analysis (TGA) of waste PCBs was carried out by using the TA Instruments SDT Q600 thermogravimetric analyzer with a nitrogen flow rate of $100 \mathrm{~mL} \mathrm{~min}^{-1}$. The heating rate of TGA was set at $20^{\circ} \mathrm{Cmin}^{-1}$, and the temperatures were kept constant at 200, 600 and $1000^{\circ} \mathrm{C}$. Scanning electron microscopy (SEM) images and electron dispersive X-ray spectroscopy (EDS) semiquantitative analysis results were obtained by using a JEOL JSM-7600F field emission scanning electron microscope.

\subsection{Economic assessment}

The economic assessment of gold recovery from waste PCBs using microwave pyrolysis and hydrometallurgical methods was carried out based on the conception of cost-benefit analysis. The electricity consumption of microwave pyrolysis was calculated according to that the experiment was conducted at a microwave power level of $350 \mathrm{~W}$ for a processing time period of $60 \mathrm{~min}$. The conversion efficiency from electrical energy to microwave energy was assumed to be $50 \%$ [26]. As for the cost of chemicals used in the hydrometallurgical experiments, the unit prices of sulfuric acid, hydrogen peroxide, thiosulfate and perchloric acid were assumed to be USD 200, 600, 200 and 1000 per tonne, respectively. The price of gold was assumed to be USD 60 per gram. Further description about the economic assessment can be seen in the following section.

\section{Results and discussion}

\subsection{Microwave pyrolysis}

To prevent the loss of precious metals and the formation of dangerous metal fines, dust containing brominated flame retardants and dioxins during the shredding or grinding pretreatment $[2,22,30]$, the waste PCBs were pretreated by microwave pyrolysis prior to hydrometallurgical metal recovery processes. Before proceeding to microwave pyrolysis experiments, the basic thermochemical property of waste PCBs was investigated by TGA. The profiles of thermogravimetry (TG) and derivative thermogravimetry (DTG) are illustrated in Fig. S3. It can be seen that the weight loss was very small when the temperature reached $200^{\circ} \mathrm{C}$, so the moisture content of waste PCBs should be quite less. The maximum weight loss rate of waste PCBs was approximately $11 \mathrm{wt} \% \mathrm{~min}^{-1}$, which occurred at $355^{\circ} \mathrm{C}$. The weight loss was approximately 19 wt $\%$ when heating to $400^{\circ} \mathrm{C}$, after which the weight of waste PCBs decreased at a much lower rate. At $1000^{\circ} \mathrm{C}$, the overall weight loss of waste PCBs was approximately $30 \mathrm{wt} \%$. For the purpose of being helpful for the following hydrometallurgical processes, it would be necessary to remove most of the volatile matter fraction of waste PCBs. Therefore, the waste PCBs should be heated to around $400{ }^{\circ} \mathrm{C}$ at least.

The maximum temperatures and heating rates of microwave pyrolysis at different microwave power levels are listed in Table 2. It should be noted that the heating rates were determined by linear regression of data from the first to the tenth minute. In general, both maximum

Table 2 Maximum temperatures and heating rates of microwave pyrolysis of waste PCBs

\begin{tabular}{lll}
\hline $\begin{array}{l}\text { Microwave power } \\
\text { level (W) }\end{array}$ & $\begin{array}{l}\text { Maximum } \\
\text { temperature }\left({ }^{\circ} \mathbf{C}\right)\end{array}$ & $\begin{array}{l}\text { Heating rate } \\
\left({ }^{\circ} \mathbf{C ~} \text { min }^{-1}\right)\end{array}$ \\
\hline 150 & 289.6 & 15.7 \\
200 & 334.2 & 19.5 \\
250 & 365.3 & 21.6 \\
300 & 382.5 & 23.4 \\
350 & 405.4 & 26.4 \\
400 & 508.9 & 30.7 \\
\hline
\end{tabular}


temperature and heating rate increased with increasing microwave power level. A straight line can be obtained when plotting microwave power level versus maximum temperature or heating rate, as illustrated in Fig. S4. These correlations can be used to predict the performance of microwave pyrolysis of waste PCBs when the microwave power level applied is either higher or lower than the range of $150-400 \mathrm{~W}$. As aforementioned, the minimum temperature required for thermal pretreatment of waste PCBs would be $400^{\circ} \mathrm{C}$, based on the result of TGA. Therefore, in this study the microwave power level of 350 W was selected for the microwave pyrolysis of waste PCBs. Besides, the temperature profile of microwave pyrolysis of waste PCBs at a microwave power level of $350 \mathrm{~W}$ is shown in Fig. S5. It can be seen that most of the temperature rising occurred during the first $10 \mathrm{~min}$, and the maximum temperature was almost reached under microwave irradiation for $30 \mathrm{~min}$. This can be regarded as the minimum processing time period for the microwave pyrolysis of waste PCBs at $350 \mathrm{~W}$. However, to remove the organic fraction of waste PCBs as much as possible, in this study all the microwave pyrolysis experiments to pretreat waste PCBs were carried out for $60 \mathrm{~min}$.

\subsection{Leaching}

After microwave pyrolysis, the copper leaching from pyrolyzed PCBs was carried out by using different concentrations of sulfuric acid. The leaching efficiencies of copper are illustrated in Fig. 2A, where the asterisk symbol represents that the lixiviant was a mixture of sulfuric acid and hydrogen peroxide. The leaching efficiency is defined by the equation as follows:
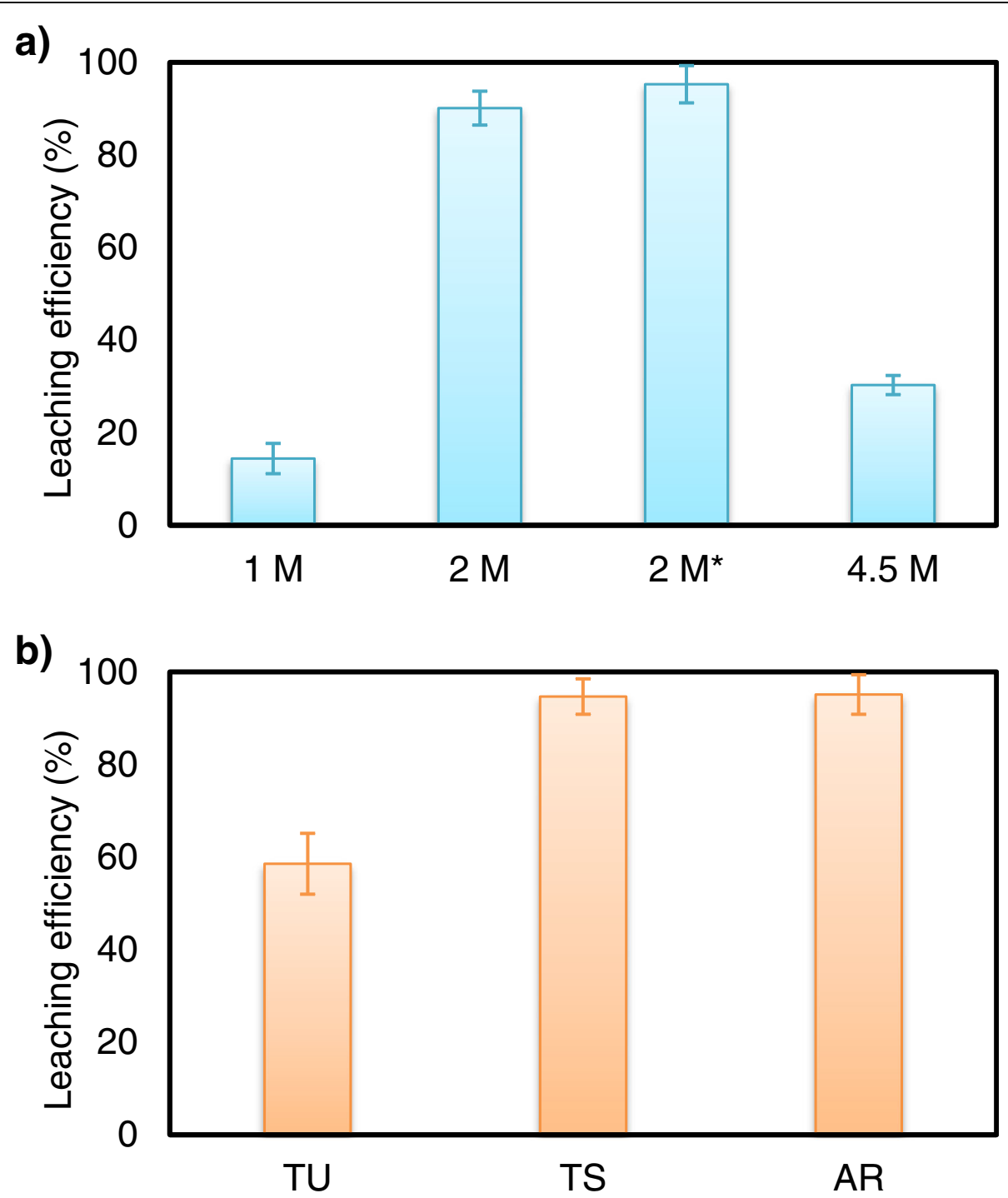

Fig. 2 Leaching efficiencies of (A) copper by using different concentrations of sulfuric acid and (B) gold by using thiourea (TU), thiosulfate (TS) and aqua regia (AR). The asterisk symbol represents that the lixiviant was a mixture of sulfuric acid and hydrogen peroxide 


$$
E_{L}=\frac{M_{L}}{M_{0} \times S / L} \times 100 \%
$$

where $E_{L}$ is the leaching efficiency, $M_{L}$ is the metal concentration in the leachate, $M_{0}$ is the metal content in the waste PCBs, and $S / L$ is the solid to liquid ratio. It can be seen that the leaching efficiencies were only approximately 14 and $30 \%$ when using 1 and $4.5 \mathrm{M}$ sulfuric acid, respectively, whereas it was as high as approximately $90 \%$ when using $2 \mathrm{M}$ sulfuric acid. When hydrogen peroxide was added to the lixiviant, the leaching efficiency of copper was further increased to approximately $95 \%$. This means that almost all of the copper contained in the pyrolyzed PCBs can be leached out by using a lixiviant composed of sulfuric acid and hydrogen peroxide. Therefore, oxidative leaching should be a feasible process for copper leaching from waste PCBs. Repeating the process may be considered to make sure the complete leaching of copper or even other base metals. The change of leaching efficiency of copper with processing time is illustrated in Fig. S6. It can be seen that in the beginning the leaching efficiency increased rapidly and reached approximately $80 \%$ within $1 \mathrm{~h}$, and then it increased at a much slower rate. Since the existence of base metals would largely hinder the leaching of precious metals, the PCBs leached by the lixiviant containing sulfuric acid and hydrogen peroxide was applied to the following second-stage leaching process for gold recovery.

The leaching efficiencies of gold from pyrolyzed PCBs using thiourea, thiosulfate and aqua regia are illustrated in Fig. 2B. In the thiourea system, ferric ions were added as an oxidant [5]:

$$
\begin{aligned}
& \mathrm{Au}+2 \mathrm{SC}\left(\mathrm{NH}_{2}\right)_{2}+\mathrm{Fe}^{3+} \rightarrow \mathrm{Au}\left[\mathrm{SC}\left(\mathrm{NH}_{2}\right)_{2}\right]_{2}^{+} \\
& \quad+\mathrm{Fe}^{2+}
\end{aligned}
$$

The complexation of gold(I) with thiourea formed a cationic complex, $\mathrm{Au}\left[\mathrm{SC}\left(\mathrm{NH}_{2}\right)_{2}\right]_{2}{ }^{+}$. The leaching efficiency of gold from pyrolyzed PCBs using thiourea was approximately $59 \%$, lower than $90 \%$ from shredded PCBs with a particle size of 100 mesh $(0.149 \mathrm{~mm})$ [23]. Therefore, thiourea leaching should be largely influenced by the particle size of waste PCBs. The dissolution of gold in a solution containing thiosulfate and ammonia is an electrochemical reaction catalyzed by cupric ions [31]:

$$
\begin{aligned}
& \mathrm{Au}+\mathrm{Cu}\left(\mathrm{NH}_{3}\right)_{4}^{2+}+5 \mathrm{~S}_{2} \mathrm{O}_{3}^{2-} \rightarrow \mathrm{Au}\left(\mathrm{S}_{2} \mathrm{O}_{3}\right)_{2}^{3-} \\
& \quad+\mathrm{Cu}\left(\mathrm{S}_{2} \mathrm{O}_{3}\right)_{3}^{5-}+4 \mathrm{NH}_{3}
\end{aligned}
$$

The cuprous ions in Eq. (3) can be oxidized by dissolved oxygen to regenerate cupric tetraammine complex ions [16]:

$$
\begin{aligned}
& 2 \mathrm{Cu}\left(\mathrm{S}_{2} \mathrm{O}_{3}\right)_{3}^{5-}+8 \mathrm{NH}_{3}+0.5 \mathrm{O}_{2} \\
& \quad+\mathrm{H}_{2} \mathrm{O} \rightarrow 2 \mathrm{Cu}\left(\mathrm{NH}_{3}\right)_{4}^{2+}+6 \mathrm{~S}_{2} \mathrm{O}_{3}^{2-}+2 \mathrm{OH}^{-}
\end{aligned}
$$

The leaching efficiency of gold using thiosulfate was approximately $95 \%$, much higher than that when using thiourea. This could be attributable to the high selectivity offered by thiosulfate leaching [13]. Although almost all of the copper was leached out during the first-stage leaching process, there would be some other base metals still contained in waste PCBs to consume thiourea, resulting in low leaching efficiency of gold. Besides, the regeneration of cupric tetraammine complex ions, as shown in Eq. (4), favors Eq. (3) to move in the direction of gold dissolution, which would play an important role in gold recovery from waste PCBs.

The leaching of gold from waste PCBs was attempted by using aqua regia as well. As shown in Fig. 2B, the leaching efficiency of gold was approximately $95 \%$. Like thiosulfate, almost all of the gold can be leached out by using aqua regia due to its strongly oxidative property. However, considering that aqua regia is highly corrosive and the wastewater produced from its applications is too acidic to be dealt with [32], the leachate produced by thiosulfate leaching of pyrolyzed PCBs was selected to be applied to the following solvent extraction process. To observe the composition of the leachate, the precipitates formed during the standstill of the leachate were analyzed by using the EDS, as shown in Table S1. After thiosulfate leaching, the precipitate was mainly composed of copper, calcium, silicon and sulfur. These metals should come from the acid leaching of waste PCBs, and the sulfur element would primarily come from the lixiviant thiosulfate. In the aqua regia leaching system, there were copper, aluminum, silicon and oxygen found in the precipitate. The compositions and metal contents of the two precipitates were different. This should be attributable to the different lixiviants used for the leaching of waste PCBs. The leaching ability and metal selectivity of the two lixiviants would be quite different from each other.

\subsection{Solvent extraction}

Through the solvent extraction process using D2EHPA, TBP, DBC and TOA organic solvents at different concentrations and $\mathrm{O} / \mathrm{A}$ ratios, the extraction efficiencies of gold are listed in Table S2. In general, solvent extraction was not able to provide satisfactory extraction of gold. The highest extraction efficiency of gold was only approximately $25 \%$, provided by solvent extraction using 1 $\mathrm{M}$ D2EHPA at an O/A ratio of $1 / 5$. The organic solvent $\mathrm{DBC}$ seems to be most inapplicable for the extraction of gold ions. The extraction efficiencies of gold were in the range of approximately $0.4-6.4 \%$ when using DBC. The low extraction efficiencies mean that most of the gold 
ions were still left in the aqueous phase after solvent extraction, which is against the purpose of increasing the recovery rate of gold as high as possible. Therefore, the solvent extraction process was not necessary for gold recovery from waste PCBs. The leachate produced by thiosulfate leaching of pyrolyzed PCBs was decided to bypass solvent extraction and directly apply to the precipitation process.

\subsection{Precipitation}

In this study, three different oxidants (hydrogen peroxide, hypochlorous acid and perchloric acid) were used to decompose the gold thiosulfate complex, $\mathrm{Au}\left(\mathrm{S}_{2} \mathrm{O}_{3}\right)_{2}{ }^{3-}$, and then to obtain a precipitate containing gold ions. Taking hydrogen peroxide as an example, the equations showing the oxidation of thiosulfate are as follows [33, 34]:

$$
\begin{aligned}
& \mathrm{H}_{2} \mathrm{O}_{2}+2 \mathrm{~S}_{2} \mathrm{O}_{3}^{2-}+2 \mathrm{H}^{+} \rightarrow \mathrm{S}_{4} \mathrm{O}_{6}^{2-}+2 \mathrm{H}_{2} \mathrm{O} \\
& 4 \mathrm{H}_{2} \mathrm{O}_{2}+\mathrm{S}_{2} \mathrm{O}_{3}^{2-} \rightarrow 2 \mathrm{SO}_{4}^{2-}+3 \mathrm{H}_{2} \mathrm{O}+2 \mathrm{H}^{+}
\end{aligned}
$$

The oxidation of thiosulfate by hydrogen peroxide is $\mathrm{pH}$ dependent. It favors the formation of tetrathionate at low $\mathrm{pH}$ values whereas favors the production of sulfate at high $\mathrm{pH}$ values [34]. The precipitation efficiencies of gold are listed in Fig. 3. Precipitation efficiency was determined according to the equation as follows:

$$
E_{P}=\frac{M_{L}-M_{S}}{M_{L}} \times 100 \%
$$

where $E_{P}$ is the precipitation efficiency, $M_{L}$ is the concentration of gold in the leachate produced by the twostage leaching of pyrolyzed PCBs, and $M_{S}$ is the concentration of gold in the supernatant obtained by the oxidative precipitation of the leachate. It can be seen that the precipitation efficiencies of gold were approximately 95 and $99 \%$ when using the oxidants of hydrogen peroxide and perchloric acid, respectively. However, it was only approximately 19\% when hypochlorous acid was used. This should be attributable to its weak oxidizing power that was not capable of decomposing the gold thiosulfate complex to a satisfactory extent. In the same way, because of the stronger oxidizing power of perchloric acid, it can provide higher precipitation efficiencies of gold than hydrogen peroxide.

Figure 3 also shows the final recovery rates of gold from waste PCBs using microwave pyrolysis, thiosulfate leaching and oxidative precipitation processes. The final recovery rate is defined by the equation as follows:

$$
R_{F}=E_{L} \times E_{P}
$$

where $R_{F}$ is the final recovery rate, $E_{L}$ is the leaching efficiency, and $E_{P}$ is the precipitation efficiency. As aforementioned, the leaching efficiency of gold from waste PCBs using thiosulfate was approximately $95 \%$. The final recovery rates of gold, which can be obtained by multiplying leaching efficiency and precipitation efficiency, were approximately 90,18 and $93 \%$ when using the oxidants of hydrogen peroxide, hypochlorous acid and perchloric acid, respectively. As aforementioned, the use of shredding or grinding process can lead to the loss of precious metals up to $40 \%$ [22]. The comparison among the recovery rates of gold in several studies is listed in Table 3. It can be seen that gold can be successfully leached out by using various lixiviants. In some cases, the

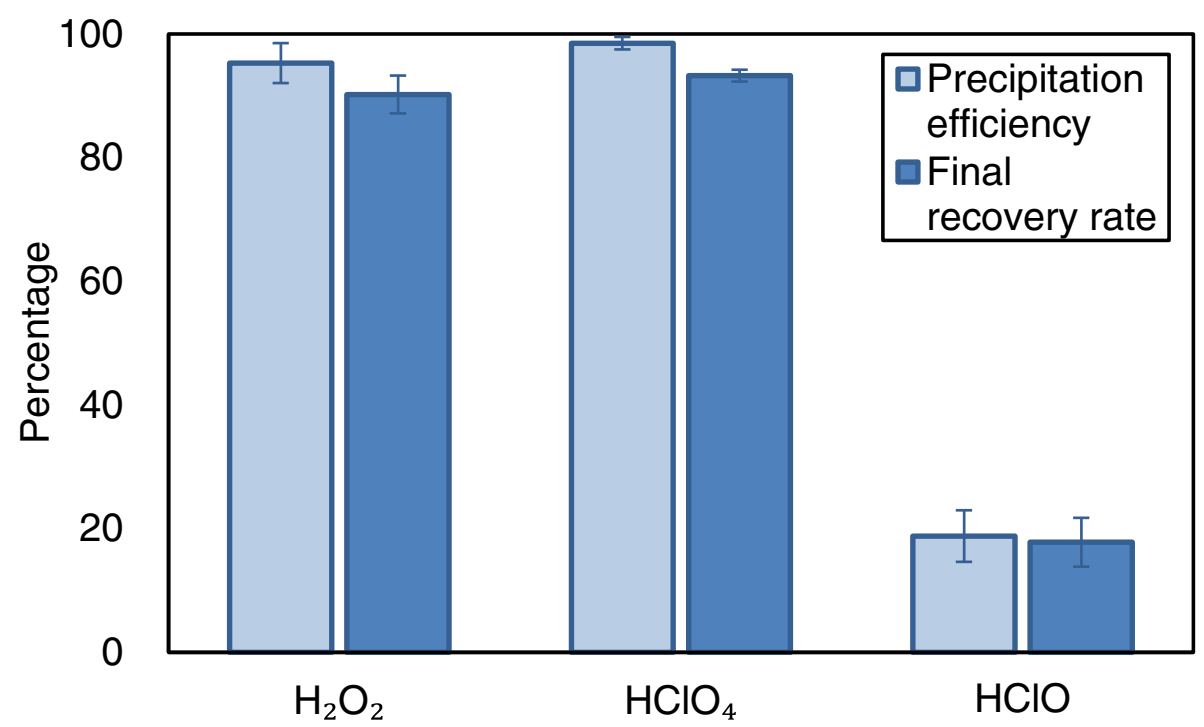

Fig. 3 Precipitation efficiencies and final recovery rates of gold 
Table 3 Studies regarding gold recovery from waste PCBs

\begin{tabular}{|c|c|c|c|c|}
\hline \multirow[t]{2}{*}{ Process } & \multirow[t]{2}{*}{ Reagent } & \multicolumn{2}{|c|}{ Recovery rate $(\%)$} & \multirow[t]{2}{*}{ Ref. } \\
\hline & & Original & Adjusted* $^{*}$ & \\
\hline Leaching & Cyanide & 95.0 & 57.0 & {$[35]$} \\
\hline Leaching & Thiourea & 90.0 & 54.0 & {$[23]$} \\
\hline Leaching & lodine-iodide & 98.5 & 59.1 & {$[21]$} \\
\hline Leaching & Aqua regia & 95.2 & 57.1 & {$[24]$} \\
\hline Leaching & DMF-CuCl $2-\mathrm{CaCl}_{2}$ system & 99.2 & 59.5 & {$[25]$} \\
\hline Precipitation & None & 99.3 & 59.6 & \\
\hline Leaching & Thiosulfate & 94.7 & 94.7 & Present study \\
\hline Leaching & Aqua regia & 95.1 & 95.1 & \\
\hline Precipitation & $\mathrm{H}_{2} \mathrm{O}_{2}$ & 95.3 & 95.3 & \\
\hline Precipitation & $\mathrm{HClO}_{4}$ & 98.5 & 98.5 & \\
\hline
\end{tabular}

*Adjusted recovery rate equals original recovery rate times (100-40\%), assuming that the loss of gold due to shredding and grinding processes is $40 \%$

recovery rate of gold can be as high as approximately $99 \%$ $[21,25]$. However, the actual recovery rate of gold would be only $60 \%$ when considering the $40 \%$ loss of gold due to shredding and grinding processes [22], which is much lower than the results shown in this study. The high recovery rates of gold in this study may imply that the loss of precious metals can be prevented by using the microwave pyrolysis technique as a pretreatment step to replace shredding and grinding. The final gold recovery rate of approximately $93 \%$ means that approximately $7 \%$ of gold in the waste PCBs can not be recovered by using microwave pyrolysis, leaching and oxidative precipitation methods sequentially. The loss of $7 \%$ would primarily include $5 \%$ of gold remained in the waste PCBs after thiosulfate leaching and $2 \%$ of gold that can not be recovered by oxidative precipitation using perchloric acid.

The SEM images of precipitates obtained by oxidative precipitation using hydrogen peroxide and perchloric acid are illustrated in Fig. 4. It can be seen that, in comparison with the precipitate produced by using perchloric acid, the composition of the precipitate produced by using hydrogen peroxide was more complicated. The small spheres with metallic luster in the precipitates should be pure metals, and the blocks without metallic luster could be sulfate or carbonate salt. The two kinds of materials can be separated based on their different sizes and densities. The contents of gold, silver and copper in the precipitates obtained by using hydrogen peroxide and perchloric acid are shown in Table S3. The other metals originally contained in the waste PCBs were not detected. When using hydrogen peroxide, the gold content of precipitate was approximately $4.4 \mathrm{wt} \%$, a little higher than that of the precipitate produced by using perchloric acid (approximately $4.0 \mathrm{wt} \%)$. However, it also contained substantial amounts of silver and copper, with the contents of approximately 18 and $30 \mathrm{wt} \%$, respectively. In the precipitate produced
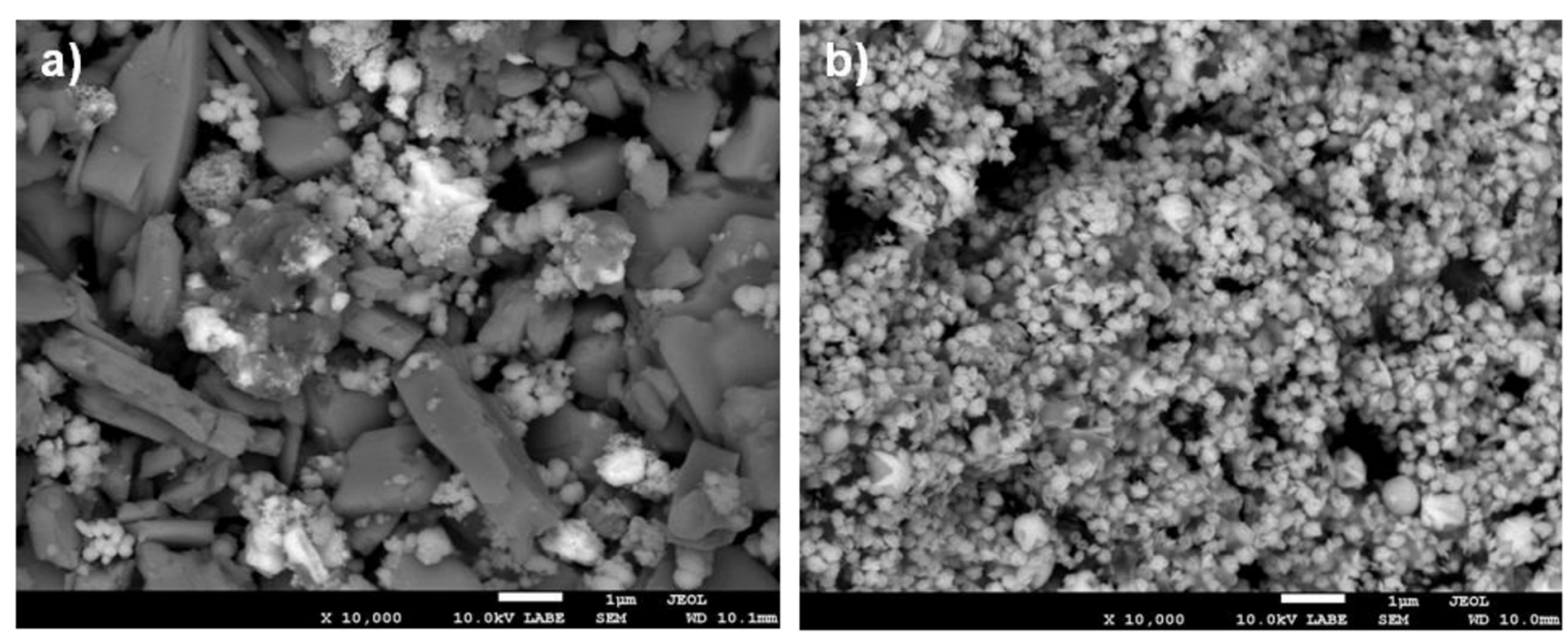

Fig. 4 SEM images of precipitates obtained by using (A) hydrogen peroxide and (B) perchloric acid 
by using perchloric acid, the contents of silver and copper were approximately 0.4 and $9.3 \mathrm{wt} \%$, respectively, much lower than those when using hydrogen peroxide. These metal contents represent that the gold purities in the oxidative precipitation products using hydrogen peroxide and perchloric acid were approximately 8 and 29\%, respectively. Therefore, using perchloric acid as an oxidant for oxidative precipitation should be able to provide higher selectivity for gold recovery. Although high gold recovery rate can be obtained by using microwave pyrolysis and hydrometallurgical methods, the selectivity and purity of gold were not satisfactory. If the acid leaching process of waste PCBs can be repeated for two or more times, the copper concentration in the finally obtained leachate and also the copper content in the precipitate will both be as low as possible, leading to high recovery and purity of gold. On the other hand, the gold purity of the oxidative precipitation product would be increased by using additional pyrometallurgical, hydrometallurgical or electrometallurgical method, which needs to be further studied to find out the best gold purity and the optimal experimental condition.

In a previous preliminary study, it has been shown that a substantial delamination of waste PCBs can be achieved by using microwave pyrolysis [28]. This delamination phenomenon would be helpful to make the leaching of metals from waste PCBs more easily and then to increase the leaching efficiencies of copper and gold. Therefore, the traditional shredding and grinding pretreatment processes would be no longer necessary to reduce the size of waste PCBs. In addition, microwave pyrolysis of waste PCBs can provide higher recovery rates of copper and gold than conventional pyrolysis [36]. This should be attributable to the rapid, efficient and selective heating of materials under microwave irradiation as aforementioned. Compare with conventional pyrolysis, the delamination phenomenon of waste PCBs can be more significant when using microwave pyrolysis [36]. Therefore, as a pretreatment process, microwave pyrolysis should be an effective method for metal recovery from waste PCBs. Nevertheless, further studies in depth are needed to thoroughly interpret the mechanisms of gold recovery from waste PCBs using microwave pyrolysis and hydrometallurgical methods.

\subsection{Economic assessment}

The processing capacity of the microwave oven used in this study was only approximately $20 \mathrm{~g}$ due to the size of reaction cavity. Nevertheless, the potential processing capacity of microwave pyrolysis of waste PCBs can be predicted by means of the correlation between heat $(Q)$ and temperature change $(\Delta T)$ as follows:

$$
Q=m c \Delta T
$$

where $m$ is the mass and $c$ is the specific heat capacity. Based on Eq. (1), a correlation between microwave power level $(P)$ and heating rate $(\Delta T / \Delta t)$ can be applied:

$$
P=m c(\Delta T / \Delta t)
$$

The plots of input energy versus temperature change and microwave power level versus heating rate are illustrated in Fig. S7. In each plot, the slope of regression line equals $m c$ in Eqs. (9) and (10). Since the specific heat capacity of waste PCBs is $0.6 \mathrm{~J} \mathrm{~g}^{-1} \mathrm{~K}^{-1}$ [37], the mass of waste PCBs can be approximately 1476 and $1225 \mathrm{~g}$ according to the correlations of input energy versus temperature change and microwave power level versus heating rate, respectively. Furthermore, the coefficient of determination $\left(R^{2}\right)$ of microwave power level versus heating rate correlation is higher than that of input energy versus temperature change correlation, so the mass of $1225 \mathrm{~g}$ should be more reliable to be regarded as the maximum processing capacity of microwave pyrolysis of waste PCBs.

The economic assessment of gold recovery from waste PCBs using microwave pyrolysis and hydrometallurgical methods was carried out based on experimental conditions and results as well as the maximum processing capacity of microwave pyrolysis as aforementioned. After microwave pyrolysis, acid leaching, thiosulfate leaching and oxidative precipitation of $1 \mathrm{t}$ of waste PCBs, approximately $168 \mathrm{~g}$ of gold can be recovered (recovery rate: 93\%). The costs would be approximately USD 69 for the energy consumption of microwave pyrolysis (assuming electricity fee USD 0.12 per $\mathrm{kWh}$ ) and approximately USD 638 for the consumption of chemicals used for hydrometallurgical processes. The gold recovered from $1 \mathrm{t}$ of waste PCBs can be sold for approximately USD 10,073 (assuming gold price USD 60 per gram), and thus the return on investment (ROI) can be as high as approximately $1400 \%$. Calculation details are shown in Table S4. The electricity fee and the unit prices of chemicals were referred to the information from the U.S. government and the global financial market that can be found online. The treatment cost of wastewater and residues was not considered in this economic assessment because other valuable materials may be also recovered after additional processes, leading to difficulty in quantifying and characterizing the final forms of these wastes. In addition, if the recovery of energy and other valuable materials in the waste PCBs are considered, the ROI of waste PCBs recycling using microwave pyrolysis and hydrometallurgical methods will be further increased.

\section{Conclusions}

As a pretreatment process to replace conventional shredding and grinding, microwave pyrolysis of waste 
PCBs was carried out at a microwave power level of 350 W for a processing time period of $60 \mathrm{~min}$ based on the experimental results of TGA and microwave heating. The metals in waste PCBs were leached out by a twostage leaching process. In the first stage, the leaching efficiency of copper was up to approximately $95 \%$ when using a lixiviant composed of sulfuric acid and hydrogen peroxide, so oxidative leaching should be a feasible process for copper recovery from waste PCBs. In the second stage, the leaching efficiencies of gold were approximately 59, 95 and $95 \%$, when using thiourea, thiosulfate and aqua regia, respectively. The high leaching efficiency of gold using thiosulfate should be attributable to the high selectivity offered by thiosulfate leaching. Considering the possible problems caused by aqua regia, the leachate produced by thiosulfate leaching of pyrolyzed PCBs was selected to be applied to the following solvent extraction and oxidative precipitation processes.

The gold ions contained in the leachate previously produced by the leaching processes were not satisfactorily extracted by using D2EHPA, TBP, DBC and TOA organic solvents. The highest extraction efficiency of gold was only approximately $25 \%$ by using D2EHPA. Therefore, solvent extraction would not be suitable for gold recovery, and the leachate was decided to bypass solvent extraction and directly apply to the oxidative precipitation process. The precipitation efficiencies of gold were as high as approximately 95 and $99 \%$ when using the oxidants of hydrogen peroxide and perchloric acid, respectively. However, it was only approximately $19 \%$ when hypochlorous acid was used, possibly due to its weak oxidizing power that was not able to sufficiently decompose the gold thiosulfate complex. The final recovery rates were approximately 90 and $93 \%$ when using the oxidants of hydrogen peroxide and perchloric acid, respectively. Therefore, high recovery rate of gold can be obtained by using sulfuric acid leaching, thiosulfate leaching and oxidative precipitation processes. The high recovery rates of gold can be attributable to the use of microwave pyrolysis that prevents the loss of gold caused by shredding and grinding processes. In addition, perchloric acid can provide higher selectivity for gold recovery than hydrogen peroxide. To achieve high recovery and purity of gold, it would be necessary to repeat the acid leaching process to let the copper concentration in the finally obtained leachate and also the copper content in the precipitate both be as low as possible.

Based on the correlation between microwave power level and heating rate, the maximum processing capacity of microwave pyrolysis of waste PCBs would be as high as $1.23 \mathrm{~kg}$. For the processing of $1 \mathrm{t}$ of waste PCBs, the costs would be approximately USD 34 for the energy consumption of microwave pyrolysis and approximately USD 638 for the consumption of chemicals used for hydrometallurgical processes. The gold recovered from $1 \mathrm{t}$ of waste PCBs can be sold for approximately USD 9600 , and thus the ROI can be as high as approximately $1400 \%$. Therefore, high economic benefit can be offered by the recycling of waste PCBs using microwave pyrolysis and hydrometallurgical methods. Although this study focused on the gold recovery from waste PCBs, the following treatments for the residues and wastewater generated during microwave pyrolysis and hydrometallurgical processes would be of great importance. Ideally, all of the materials contained in the waste PCBs can be recovered as resources. However, due to the concerns of processing difficulty, health risk and economic efficiency, proper treatments for the residues and wastewater should be necessary and inevitable.

\section{Supplementary Information}

The online version contains supplementary material available at https://doi. org/10.1186/s42834-022-00118-X

\section{Additional file 1.}

Acknowledgements

The authors gratefully acknowledge the financial support from the Ministry of Science and Technology, Taiwan, R.O.C. via the contract MOST 107-2221-E002-010-MY3.

\section{Authors' contributions}

Yu-Fong Huang and Szu-Ling Chou conducted laboratory experimental studies. Yu-Fong Huang drafted the manuscript. Shang-Lien Lo critically reviewed and edited the final version of the manuscript. All authors have read and approved the final manuscript.

Funding

This work was supported by the Ministry of Science and Technology, Taiwan, R.O.C. (grant number 107-2221-E-002-010-MY3).

Availability of data and materials

All data generated or analyzed during this study are included in this article and its supplementary materials file. The raw data are available from the corresponding author upon reasonable request.

\section{Declarations}

Competing interests

The authors declare they have no competing interests.

Received: 16 July 2021 Accepted: 29 December 2021

Published online: 15 January 2022

References

1. Balde CP, Forti $V$, Gray $V$, Kuehr R, Stegmann P. The global e-waste monitor - 2017. Bonn, Geneva, Vienna: United Nations University, International Telecommunication Union, International Solid Waste Association; 2017.

2. Hsu E, Barmak K, West AC, Park AHA. Advancements in the treatment and processing of electronic waste with sustainability: a review of metal extraction and recovery technologies. Green Chem. 2019;21:919-36.

3. Forti V, Balde CP, Kuehr R, Bel G. The global e-waste monitor 2020: quantities, flows and the circular economy potential. Bonn, Geneva, Rotterdam: United Nations University, United Nations Institute for Training and Research, International Telecommunication Union, International Solid Waste Association; 2020.

4. Lu Y, Xu ZM. Precious metals recovery from waste printed circuit boards: a review for current status and perspective. Resour Conserv Recy. 2016;113: 28-39. 
5. Li H, Eksteen J, Oraby E. Hydrometallurgical recovery of metals from waste printed circuit boards (WPCBs): current status and perspectives - a review. Resour Conserv Recy 2018;139:122-39.

6. Guo J, Luo XM, Tan SF, Ogunseitan OA, Xu ZM. Thermal degradation and pollutant emission from waste printed circuit boards mounted with electronic components. J Hazard Mater. 2020;382:121038.

7. Zhang K, Schnoor JL, Zeng EY. E-waste recycling: where does it go from here? Environ Sci Technol. 2012;46:10861-7.

8. Chen MJ, Wang JB, Chen HY, Ogunseitan OA, Zhang MX, Zang HB, et al. Electronic waste disassembly with industrial waste heat. Environ Sci Technol. 2013;47:12409-16.

9. Wang X, Gaustad G. Prioritizing material recovery for end-of-life printed circuit boards. Waste Manage. 2012;32:1903-13.

10. Wang HD, Zhang SH, Li B, Pan D, Wu YF, Zuo TY. Recovery of waste printed circuit boards through pyrometallurgical processing: a review. Resour Conserv Recy. 2017;126:209-18.

11. Qiu RJ, Lin M, Ruan JJ, Fu YG, Hu JQ, Deng ML, et al. Recovering full metallic resources from waste printed circuit boards: a refined review. J Clean Prod. 2020;244:118690

12. Tuncuk A, Stazi $V$, Akcil A, Yazici EY, Deveci H. Aqueous metal recovery techniques from e-scrap: hydrometallurgy in recycling. Miner Eng. 2012;25: 28-37.

13. Cui $\mathrm{H}$, Anderson CG. Literature review of hydrometallurgical recycling of printed circuit boards (PCBs). J Adv Chem Eng. 2016;6:1000142.

14. Bruckner L, Frank J, Elwert T. Industrial recycling of lithium-ion batteries - a critical review of metallurgical process routes. Metals-Basel. 2020;10:1107.

15. Sethurajan M, van Hullebusch ED, Fontana D, Akcil A, Deveci H, Batinic B, et al. Recent advances on hydrometallurgical recovery of critical and precious elements from end of life electronic wastes - a review. Crit Rev Env Sci Tec. 2019:49:212-75.

16. Ghosh B, Ghosh MK, Parhi P, Mukherjee PS, Mishra BK. Waste Printed Circuit Boards recycling: an extensive assessment of current status. J Clean Prod. 2015;94:5-19.

17. Kaya M. Recovery of metals and nonmetals from electronic waste by physical and chemical recycling processes. Waste Manage. 2016;57:64-90.

18. Guo JY, Guo J, Xu ZM. Recycling of non-metallic fractions from waste printed circuit boards: a review. J Hazard Mater. 2009;168:567-90.

19. Lixandru A, Venkatesan $P$, Jonsson C, Poenaru I, Hall B, Yang $Y$, et al. Identification and recovery of rare-earth permanent magnets from waste electrical and electronic equipment. Waste Manage. 2017;68:482-9.

20. Sahan M, Kucuker MA, Demirel B, Kuchta K, Hursthouse A. Determination of metal content of waste mobile phones and estimation of their recovery potential in Turkey. Int J Env Res Pub He. 2019;16:887.

21. Xiu FR, Qi YY, Zhang FS. Leaching of $\mathrm{Au}, \mathrm{Ag}$, and $\mathrm{Pd}$ from waste printed circuit boards of mobile phone by iodide lixiviant after supercritical water pre-treatment. Waste Manage. 2015:41:134-41.

22. Jiang $P$, Harney $M$, Song $Y X$, Chen $B$, Chen $Q$, Chen TN, et al. Improving the end-of-life for electronic materials via sustainable recycling methods. Procedia Environ Sci. 2012:16:485-90.

23. Li JY, Xu XL, Liu WQ. Thiourea leaching gold and silver from the printed circuit boards of waste mobile phones. Waste Manage. 2012;32:1209-12.

24. Hubau A, Chagnes A, Minier M, Touze S, Chapron S, Guezennec AG. Recycling-oriented methodology to sample and characterize the metal composition of waste Printed Circuit Boards. Waste Manage. 2019;91:62-71.

25. Wang RX, Zhang CL, Zhao YF, Zhou YJ, Ma E, Bai JF, et al. Recycling gold from printed circuit boards gold-plated layer of waste mobile phones in "mild aqua regia" system. J Clean Prod. 2021;278:123597.

26. Haque KE. Microwave energy for mineral treatment processes - a brief review. Int J Miner Process. 1999:57:1-24.

27. Jones DA, Lelyveld TP, Mavrofidis SD, Kingman SW, Miles NJ. Microwave heating applications in environmental engineering - a review. Resour Conserv Recy. 2002;34:75-90

28. Huang YF, Lo SL. Energy recovery from waste printed circuit boards using microwave pyrolysis: product characteristics, reaction kinetics, and benefits. Environ Sci Pollut R. 2020;27:43274-82.

29. Huang YF, Chiueh PT, Kuan WH, Lo SL. Effects of lignocellulosic composition and microwave power level on the gaseous product of microwave pyrolysis. Energy. 2015;89:974-81.

30. Chancerel P, Meskers CEM, Hageluken C, Rotter VS. Assessment of precious metal flows during preprocessing of waste electrical and electronic equipment. J Ind Ecol. 2009;13:791-810.
31. Cui JR, Zhang LF. Metallurgical recovery of metals from electronic waste: a review. J Hazard Mater. 2008;158:228-56.

32. Petter PMH, Veit HM, Bernardes AM. Evaluation of gold and silver leaching from printed circuit board of cellphones. Waste Manage. 2014:34:475-82.

33. Schiller JE. A new reaction of cyanide with peroxide and thiosulfate at $\mathrm{pH}$ 7-9. Inorg Chem. 1987;26:948-50.

34. Lu YC, Gao QY, Xu L, Zhao YM, Epstein IR. Oxygen-sulfur species distribution and kinetic analysis in the hydrogen peroxide-thiosulfate system. Inorg Chem. 2010:49:6026-34

35. Quinet P, Proost J, Van Lierde A. Recovery of precious metals from electronic scrap by hydrometallurgical processing routes. Miner Metall Proc. 2005;22:17-22.

36. Huang YF, Pan MW, Lo SL. Hydrometallurgical metal recovery from waste printed circuit boards pretreated by microwave pyrolysis. Resour Conserv Recy. 2020;163:105090

37. Esfandyari A, Bachy B, Raithel S, Syed-Khaja A, Franke J. Simulation, optimization and experimental verification of the over-pressure reflow soldering process. Procedia CIRP. 2017;62:565-70.

\section{Publisher's Note}

Springer Nature remains neutral with regard to jurisdictional claims in published maps and institutional affiliations.
Ready to submit your research? Choose BMC and benefit from:

- fast, convenient online submission

- thorough peer review by experienced researchers in your field

- rapid publication on acceptance

- support for research data, including large and complex data types

- gold Open Access which fosters wider collaboration and increased citations

- maximum visibility for your research: over $100 \mathrm{M}$ website views per year

At $\mathrm{BMC}$, research is always in progress.

Learn more biomedcentral.com/submissions 